\title{
Understanding reasons for low HIV testing services uptake among tertiary students in university in South Africa
}

\author{
Shonisani Elizabeth Tshivhase, Takalani Makuya, Fhatuwani James Takalani \\ University of Venda, Thohoyandou, Limpopo, South Africa
}

\begin{abstract}
Introduction: The main entry point for human immunodeficiency virus (HIV) and acquired immune deficiency syndrome (AIDS) prevention, care, and treatment is through HIV testing services. Despite undeniable benefits and increased availability of HIV testing services, uptake remains low among students. The purpose of the study was to determine factors contributing to low HIV testing services uptake among tertiary students in a university in South Africa.

Material and methods: A cross-sectional study was conducted among tertiary students to determine factors contributing to low HIV testing services uptake. A total of 306 eligible students from the School of Health Sciences in a South African university were selected through a systematic random sampling technique. Data collected were analyzed using SPSS version 24 . Ethical considerations were ensured throughout the study.
\end{abstract}

Results: Findings of the study showed that out of 306 respondents, 204 (67\%) were females and 102 $(33 \%)$ males. The majority $(68 \%, n=208)$ of the students were between the age of 18 and 24 years. About 135 (44\%) respondents were tested for HIV as compared to 171 (56\%) who were not tested. Respondents showed good knowledge about HIV testing services (HTS), and their attitude was positive. HIV and AIDS-related stigma, fear of potential HIV-positive results, and negative attitude of healthcare service providers were cited as contributory factors to low uptake of HTS.

Conclusions: Despite the adequate knowledge about HTS and high awareness campaigns, HIV uptake of HTS remained low among the respondents. Therefore, the use of various forms of media, including campus radio and newsletters to promote uptake of HTS among university students is recommended.

Key words: acquired immunodeficiency syndrome, students, human immunodeficiency virus, HIV testing services, stigma.

\section{Introduction}

The most relevant strategy for minimizing the spread of human immunodeficiency virus (HIV) infection in South Africa is HIV counselling and testing (HCT). HCT is the main strategy for HIV surveillance, prevention, and treatment pro-

Address for correspondence: Shonisani Elizabeth Tshivhase, University of Venda, Thohoyandou, Limpopo, South Africa, e-mail: tshivhasese@gmail.com

grams. Studies have indicated that the spread of HIV and acquired immune deficiency syndrome (AIDS) among young adult university students is a major health concern in subSaharan Africa (SSA). Students lifestyles on university campuses put them at high-risk of contracting HIV $[1,2]$. Approximately, 36.7 million people worldwide live with HIV

Article history:

Received: 22.06.2020

Received in revised form: 06.05.2021

Accepted: 07.05.2021

Available online: 30.12 .2021
International Journal of HIV-Related Problems

HIV \& AIDS

R e v i e w 
and AIDS, and an estimated 2.1 million people become newly infected globally [3]. According to the World Health Organization (WHO) [4], the percentage of people who know their HIV status is currently at $60 \%$. The remaining $40 \%$, which is over 14 million people, still need to access HIV testing services (HTS). The burden of HIV and AIDS necessitates the implementation of various prevention strategies. HTS is one of the main strategies of preventing the spread of the disease, and it has been introduced in many settings to help individuals become aware of their HIV status [5].

HTS has become an entry point for HIV prevention and control, care, treatment, and support services. It is an integral part of the global response to the HIV and AIDS epidemic. HTS refer to full range of services that are provided with HIV testing, such as pre-test and post-test counselling, coordination with laboratory services to support quality assurance and delivery of correct results, and linkage to appropriate HIV prevention, treatment, and care services as well as other clinical and support services [6].

HTS is globally accepted as both primary and secondary prevention strategy. As a primary prevention strategy, it helps HIV-negative individuals to adopt healthy lifestyles that reduce the risk for HIV infection, such as safe sex. As a secondary strategy for prevention, HTS assists HIV-positive individuals to implement healthy sexual behaviors to prevent re-infections. Also, it helps those who have tested positive to access treatment and related services [4]. Furthermore, HTS has been identified as one of the best strategies for educating individuals about HIV- and AIDS-related issues. HTS not only allows individuals to test for HIV and subsequently know their status, but it also permits individuals to obtain knowledge on healthier sex choices.

Individuals, who do not go for HTS, may come to learn of their HIV-positive status when they are already sick, and they are more likely to experience various psychological and emotional responses, including anger, denial, aggression, depression, and social withdrawal. These responses may adversely affect student's studies due to painful process of adjusting to a new life with HIV infection. Other students may even engage in riskier behaviors, such as deliberately infecting others with the disease, so that they will not 'die alone'. Moreover, other students who discover that they are HIV-positive when they become sick, may experience low self-esteem and believe that they would no longer achieve their academic goals $[7,8]$.

Although HTS is available in public health facilities and through non-medical sites and private sector, its' uptake in South Africa and globally is low, mainly due to social stigma and attitude associated with HIV and AIDS [9]. Various studies on HTS among university students indicated that despite a high-level of knowledge about HTS among tertiary students, its' utilization was minimal. In Thailand, Khawcharoen et al. [10] found that many students did not attend HTS and were therefore unaware of their HIV serostatus.

In Georgia, university students acknowledged the significance of HTS utilization. However, although the attitude towards HTS was generally positive, it did not automatically translate to HTS uptake. Common reasons for non-utilization of such services include stigma associated with HIV, cost, and distance as well as low-risk perception among students $[2,11]$.

In most African countries, such as Ethiopia, Nigeria, Zimbabwe, and South Africa, only a few university students have reported attending HTS. Even though most students knew about HTS and its' benefits in the prevention and control of HIV and AIDS spread, studies performed among Ugandan and Zambian students revealed a poor uptake of HTS of between $10 \%$ and $14 \%$, respectively $[9,12]$.

In South Africa, about $74 \%$ of higher education institutions had already established HTS by the end of 2015, and $69 \%$ were offering these services for free [13]. Despite this initiative, HTS uptake remains low among students. In Kwazulu-Natal and Limpopo, universities indicate that although students have adequate information about HTS, only a few make use of such services. The main source of such information is the media, such as radio and television. Low-rate of HTS utilization is linked to various factors, including stigma associated with HIV-positive status, fear of living with HIV, lack of adequate information regarding HTS, confidentiality, fears surrounding HIV and AIDS testing, and a belief that one is not and cannot be infected with HIV $[12,14,15]$. Therefore, the current study sought to understand reasons contributing to low HIV counselling and testing uptake among health science students at the University of Venda.

\section{Material and methods}

\section{Study design}

A cross-sectional descriptive research design was used to investigate factors contributing to low HTS uptake amongst health sciences students.

\section{Study setting}

The study was conducted at the University of Venda, which is situated in Vhembe District of the Limpopo Province, South Africa. The institution is located in a major commercial town of Thohoyandou, which has a high population density and is largely characterized by poor physical infrastructure. There are also medium and small formal and informal settlements around the town. The town attracts a lot of businessmen in transit who sometimes engage in transactional sex with students from the University of Venda. Furthermore, activities, such as prostitution, are prevalent because the University of Venda is just $2.5 \mathrm{~km}$ from the Khoroni Hotel. There is only one healthcare center situated approximately $6 \mathrm{~km}$ away from the University that provides HIV services, including HTS. The campus has a primary healthcare facility offering services, such as HTS, support groups for HIV-positive individuals, assessment, and referral for mental healthcare issues, amongst other services. 


\section{Study population}

Target population for this study was students from the University of Venda, and accessible population was the School of Health Sciences' students registered for the 2018 academic year. Students of all genders were included in the study, and students from other schools were not included into the study.

\section{Sampling}

The respondents were sampled from five departments of the School of Health Sciences. The study involved both male and female respondents from the first level to the post-graduate level of study, and systematic random sampling was applied for selection of respondents. The total sample size for the study was 306 students.

\section{Procedure}

Before completing a questionnaire, the respondents were requested to complete all applicable questions in full, to complete the questionnaire independently, and to return it to the researcher upon completion.

\section{Data collection instrument}

The questionnaire was validated by a field experts before its' use. The questionnaire was in English language, and was not translated to any other language since all respondents presented competent English. A self-administered questionnaire consisted of close-ended questions, which were divided into a demographic section, knowledge, attitude, and practice of respondents towards HTS uptake as well as factors contributing to low HTS uptake. To test for clarity, feasibility, and appropriateness, the questionnaire was pre-tested among 31 students of the target population before its' implementation into the study.

\section{Data analysis}

Upon being returned, the completed questionnaires were scrutinized. The researcher used codes rather than respondents' names, and data was checked by frequency to identify missing or incorrect values. These that were not properly completed, were excluded, and all completed questionnaires were collated and coded starting from 001 to 306 . Data was then captured into Statistical Package for Social Sciences (SPSS) software, version 25, descriptive and inferential statistics were applied after data verification.

\section{Ethical considerations}

The research project was presented to the School Higher Degrees Committee for recommendation to the University Higher Degrees Committee for approval. The University of Venda Ethics Committee evaluated the project, and issued an ethical clearance with No. SHS/18/PH/28/0811. Written informed consent was obtained from participants, who were informed about the voluntary nature of participation in the study and their right to withdrawal from their involvement at any time, with no consequences. Confidentiality and anonymity were maintained by not disclosing identities and locations of respondents. Participants were not categorized based on their sex, age, religion, ethnicity, or any other category.

\section{Results}

Out of 316 questionnaires that were distributed, 306 questionnaires were satisfactorily filled by the respondents, thus resulting in a response rate of $97 \%$. The remaining ten questionnaires were poorly completed and were discarded. Of the 306 respondents analyzed, $204(67 \%)$ were females and $102(33 \%)$ were males. Majority $(68 \%, n=208)$ of the students were between the age of 18 and 24 years, followed by eighty (26\%) students who were between 25 and 32 years, and 18 (6\%) participants were between 33 and 44 years. Most of the respondents $(90 \%, n=275)$ were not married, and the remaining $29(10 \%)$ were married. More than half 159 (52\%) of the students were at their first and second levels of study, followed by 119 (39\%) students who were on their third and fourth levels, with $9 \%$ postgraduate students. Two hundred and eighty-nine (94\%) students reported being Christians, while the other 17 were non-Christians (6\%). This section assessed knowledge of the participants regarding HIV testing services (Table 1).

Two hundred and eighty-six (93\%) respondents were aware of HTS. Among those aware of HTS, their prime sources of HTS information were awareness campaigns ( $n=141,49 \%)$, clinic $(n=106,37 \%)$, and the media $(n=39$, $14 \%)$. Among those that have heard of HTS, the majority $(90 \%, n=273)$ knew the places where HTS could be accessed. This study showed that most respondents $(n=264$, $87 \%)$ were aware of the importance of HTS, and more than half ( $n=155,54 \%)$ of them indicated that HTS help to discover HIV status. Moreover, 66 (23\%) students stated that HTS prevents the spread of HIV and AIDS, and 11 (4\%) indicated it helps to plan one's future.

Most of the respondents $(n=284,93 \%)$ mentioned that the most common modes of HIV transmission are unsafe sex, sharing of needles, and mother-to-child transmission, as shown in Table 2. Of the 286 students, two hundred and forty-nine (87\%) considered taking HIV test as the best way to know their HIV status, followed by $9 \%$ of students, who indicated doctor's examination, and five percent who said, 'looking sick'. Out of the 306 participants, 233 (76\%) agreed that HTS services are necessary to learn about one's status, while 73 (24\%) disagreed. More than half of the respondents ( $n=193,63 \%)$ indicated HTS as not necessary if one is faithful to a partner. $160(54 \%)$ of the students agreed that they intend to go for HTS sometime in the future, while less than half $(n=140,46 \%)$ did not agree. One hundred and eightyfour $(60 \%)$ participants agreed that they would utilize HTS only if given incentives. 
Table 1. Knowledge of respondents regarding HIV testing services (HTS), N = 306

\begin{tabular}{|c|c|c|}
\hline Statement/Category & $n$ & $\%$ \\
\hline \multicolumn{3}{|l|}{ Have you ever heard of HIV testing services (HTS)? } \\
\hline Yes & 286 & 93.4 \\
\hline No & 20 & 6.5 \\
\hline \multicolumn{3}{|l|}{ Source of information } \\
\hline Media & 39 & 14.0 \\
\hline Clinics & 106 & 37.0 \\
\hline Awareness campaign & 141 & 49.0 \\
\hline \multicolumn{3}{|l|}{ Common mode of HIV transmission } \\
\hline Unsafe sex & 284 & 93.0 \\
\hline Sharing of needles & 11 & 3.6 \\
\hline Mother-to-child transmission & 11 & 3.6 \\
\hline \multicolumn{3}{|l|}{ Ways of finding out if one is infected with HIV/ AIDS } \\
\hline Taking an HIV test & 249 & 86.9 \\
\hline Doctor's examination & 22 & 7.8 \\
\hline Looking sick & 15 & 5.2 \\
\hline \multicolumn{3}{|l|}{ The importance of HIV testing services } \\
\hline It helps one to know own HIV status & 155 & 54.1 \\
\hline It helps to prevent the spread of HIV/ AIDS & 66 & 23.0 \\
\hline It helps one to receive treatment if tested positive & 54 & 18.8 \\
\hline Helps to plan one's future & 11 & 3.8 \\
\hline
\end{tabular}

Table 2. The attitude of respondents towards HIV testing services $(N=306)$

\begin{tabular}{|c|c|c|c|c|}
\hline \multirow[t]{2}{*}{ Statement } & \multicolumn{2}{|c|}{ Agree } & \multicolumn{2}{|c|}{ Disagree } \\
\hline & $n$ & $\%$ & $n$ & $\%$ \\
\hline It is necessary to go for HIV testing services to learn about one's status & 233 & 76.0 & 73 & 24.0 \\
\hline HIV testing services are not necessary if you are faithful to only one partner & 113 & 37.0 & 193 & 63.0 \\
\hline I intend going for HIV testing services sometime in future & 166 & 54.2 & 140 & 45.7 \\
\hline I can only go for HIV testing services if I am sick & 50 & 50.0 & 153 & 50.0 \\
\hline I can only utilize HIV testing services if they are offering incentives & 184 & 60.0 & 122 & 40.0 \\
\hline
\end{tabular}

About 171 (56\%) of the respondents had not been tested for HIV compared to 135 (44\%) who had been tested, as depicted in Table 3. Among those who had been tested, just over half (51\%) have been tested for HIV once only, while $15 \%$ at least 3 times. Most of the respondents ( $n=107,79 \%)$ indicated that their reason for HIV testing was to know their status, whereas $12(9 \%)$ stated that it was indicated by healthcare provider. About half (51\%) of the students feared HIV-positive results, whereas $44(26 \%)$ were afraid of the stigma. Furthermore, $214(70 \%)$ of the participants did not think they were at risk of being infected with HIV.

\section{Discussion}

Although HTS uptake amongst young people remains low, voluntary HIV counselling and testing is a key strategy towards HIV prevention. It is important to measure HTS utilization among the youth, not only because of their susceptibility to HIV, but also because they might experience some challenges in accessing HTS $[16,17]$. The current study revealed that female students (67\%) represent the greatest percentage of the study population than their male counterparts (33\%). Moreover, thirty-one percent of female students had been tested for HIV compared to only thirteen percent of male students. This can be attributed to the fact that men and women have different health-seeking behaviors. Women seek medical help and visit healthcare facilities more often than men.

Similar findings were reported in Tanzania and Nigeria, where voluntary counselling test (VCT) uptakes by female students were greater than by male students. These studies further indicate that more females than males utilized HTS $[1,16]$. Additionally, more females had more favorable attitude to- 
Table 3. Factors contributing to low HIV testing services uptake $(N=306)$

\begin{tabular}{|c|c|c|}
\hline Variable/Category & $n$ & $\%$ \\
\hline \multicolumn{3}{|l|}{ Have you ever been tested for HIV? } \\
\hline Yes & 135 & 44.1 \\
\hline No & 171 & 55.9 \\
\hline \multicolumn{3}{|c|}{ How many times have you been tested for HIV? } \\
\hline Once & 69 & 51.4 \\
\hline Twice & 45 & 33.3 \\
\hline Three times and above & 21 & 15.2 \\
\hline \multicolumn{3}{|l|}{ Reasons for testing $(n=135)$} \\
\hline To know my status & 107 & 78.9 \\
\hline I had engaged in unprotected sex & 16 & 12.0 \\
\hline It was healthcare provider's advice & 12 & 9.2 \\
\hline \multicolumn{3}{|c|}{ Reasons for not wanting to be tested for HIV $(n=171)$} \\
\hline Fear of positive results & 87 & 51.0 \\
\hline Fear of stigma & 44 & 26.0 \\
\hline Fear of attitude of healthcare provider & 28 & 16.0 \\
\hline Distance & 12 & 7.0 \\
\hline \multicolumn{3}{|l|}{ Do you think you are at risk of HIV infection? } \\
\hline Yes & 92 & 30.1 \\
\hline No & 214 & 69.9 \\
\hline
\end{tabular}

wards HTS and employed it, as demonstrated by Mulu et al. [18]. However, in Arusha, Tanzania, a study revealed different results, in which more males $(69.8 \%)$ than females (30.3\%) tested for HIV [19].

Age is a determinant in the utilization of HTS in this study setting. These findings were confirmed by the high-rate of students between 18-24 years, who utilized HTS compared to students who were 33 years and older. About $68 \%$ of the respondents in the 18-24 age group had gone for HIV testing and counselling. These findings might be because young people are more exposed to HIV education, which allows them to recognize the importance of knowing their HIV status.

Several studies have shown that age is a determinant in the utilization of HTS by most university students. For example, Museve et al. [20] in Kenya and Sanga et al. [16] observed that a huge proportion of respondents who had utilized HTS were in the age group of 18-25 years. Bayray [21] in Ethiopia and Asante [22] in Accra, Ghana, found that most respondents between 21-25 years were more willing to utilize HTS. However, Haddison et al. [23] revealed that VCT uptake decreased with age. They claimed that young people hesitated to go for HIV testing because of fear of test results, as they were more sexually active. Also, there was an increased perception of HIV and AIDS risk among individuals, who were engaged in long-term relationships and have future plans with their partners, hence causing an increase in HTS utilization [24].

The current study also revealed that a high percentage of $3^{\text {rd }}$ and $4^{\text {th }}$ level students utilized HTS than level 1-2 stu- dents. This means that the rate of HTS uptake tends to increase with the level of education. Similarly, Gadegbeku et al. [25] found that fourth-year students were more likely to go for HIV testing services compared to their second-year counterparts. Nubed and Akoachere [26] also reported that a high-level of education was associated with an increased level of HIV knowledge, which may subsequently lead to a more favorable attitude towards the utilization of HTS. Several studies have shown that a positive attitude towards the use of HTS did not automatically lead to an increased uptake of such services [27-29].

HTS awareness among the respondents in the current study was high (93\%), corresponding with previous studies, which have reported high awareness of HTS among students in tertiary institutions. For example, Ogaji et al. [30] in Nigeria and Addis et al. [31] in Ethiopia reported that $90 \%$ of respondents were aware of HTS and knew where to access HTS. By contrast, in Abia State, Nigeria, Onyeonoro et al. [2] reported a low-rate of $59 \%$ of HTS awareness amongst tertiary students. Also, main sources of HTS information were awareness campaigns, followed by clinics. Surprisingly, the media presented the lowest percentage $(14 \%)$ as a source of HTS information in this study. One would expect many students to obtain the information from the media, like in many other tertiary institutions, as young people frequently browse the Internet. The current study is inconsistent with several previous studies, which revealed that mass media, such as television, radio, internet, and magazines, was the main source of HTS information [2, 14, 32]. 
The majority (93\%) of the respondents knew about the importance of HIV testing services; half of them indicated that HTS have helped people to know their HIV status, followed by $23 \%$ who said HTS helped people to prevent the spread of HIV/AIDS. Similar data was indicated by WHO, UNAIDS [33], indicating that HTS is essential in helping individuals to be aware of their HIV status, and HTS are a great linkage to HIV prevention, treatment, care, and support services. Most respondents in this study had a good knowledge about HIV/AIDS and HTS. A high proportion (93\%) of the participants identified unsafe sex as the common mode of HIV transmission, whereas a small proportion of the students believed sharing needles and mother-tochild transmission represented the common modes of HIV transmission.

Several studies have shown that most students were adequately informed about common modes of HIV transmission. A study conducted in Qatar assessed university students' knowledge and attitude towards HIV and AIDS, and indicated that most respondents could identify unprotected sex as a common mode of HIV transmission [32]. Similarly, Choudhary et al. [34] revealed that unsafe sexual intercourse was identified as the main mode of HIV transmission.

With regards to discovering one's HIV status, most of the participants (87\%) indicated taking an HIV test as a way of finding out one's status. Other respondents felt that 'looking sick' could be a way of finding out if one was infected with HIV. However, Strauss et al. [35] reported that the only way to discover HIV status is through an HIV test. Unfortunately, there is still a misconception that one can tell if someone is living with HIV, if the individual 'looks sick'. For instance, people infected with HIV can have the disease for many years before their immune system becomes weak and symptoms start to manifest $[35,36]$.

The present study discovered that most respondents showed a positive attitude towards HTS. Most of the students $(76 \%)$ said that it was necessary to attend HIV testing services to learn about HIV status. Particularly, 64\% of the respondents disagreed with a view that HTS was not necessary if one was faithful to a partner. This is an indication of a positive attitude towards HTS. HIV testing services are intended not just for a specific group of people, but for everybody. Similar findings were reported in other higher institutions of learning in South Africa and Nigeria. Different studies indicated that respondents showed a positive attitude towards HTS and their use [30,37], which shows that university students have a positive attitude and willingness to utilize HIV testing services. Interestingly, in Tanzania, Meda [38] found that some respondents had misconceptions about HIV/AIDS transmission and beliefs that these diseases could only be transmitted through sexual intercourse. They associated HTS with sex, and felt that it was not necessary if one was faithful to one's partner.

The present study also found that around $40 \%$ of the respondents agreed that they would go for HTS if they were sick. Contrastingly, in Ethiopia, Woldeyohannes et al. [39] revealed that most respondents believed one should go for HTS at any given time, regardless of feeling sick. Furthermore, the current study showed that only a few respondents supported the view that one should utilize HTS if becomes ill. Various motivations has been shown to increase uptake of HTS; however, studies evaluating the relationship between the use of financial incentives and uptake of HTS are limited [40, 41].

The current study revealed that more than half (56\%) of the respondents had not utilized HTS, despite having adequate knowledge about HIV testing services. This result was consistent with study findings by Jali et al. [15], which showed that most of participants were well-informed about HIV testing services, though only few had utilized the services. Furthermore, these results could be linked to several barriers, including inaccurate perception of risk, stigma, fear of potential positive diagnosis, and people's perceptions towards consequences of living with HIV, which affected the utilization of HIV testing services among students [42]. Khalifa et al. [42] also discovered that most of respondents had undergone HIV testing only once, as compared to $15 \%$ who were tested 3 times and more. Similarly, in Kenya, Museve et al. [20] observed a low number of students undertaking repeat HIV testing. On the other hand, those who tested positive may go for a repeat visit because of denial or for confirmation of results [20].

Respondents indicated that they did HIV testing to know their HIV status or after engaging in unprotected sex. This suggests that students are concerned about their relationships. These findings corresponded with a South African study by Makhubele et al. [37] and a Nigerian study by Onyeonoro et al. [2], who revealed that most students went for HIV testing because they wanted to know their HIV status. Apart from using HTS to know their HIV status, some students used HTS just to satisfy their curiosity [20].

Alternatively, the reason for respondents not wanting to be tested for HIV, included fear of potential positive result, stigma, and fear of negative attitudes of health workers. There is a persistent stigma around the use of HTS, and this can act as a significant barrier in the uptake of HIV testing services. Significantly, in South Africa, the government has implemented mass HIV testing campaigns. HIV- and AIDS-related stigma has been associated with delays in testing or a decision not to utilize HTS [43].

Lin et al. [44] stated that some students were afraid of testing positive, how family and friends would react toward them if learned about their HIV-positive status, and what living with HIV would mean for their future. Furthermore, most individuals were scared that family and friends would no longer want to associate with them. Consequently, fear of positive result has been linked with lower uptake of HTS. Similar results were reported by Mbengo [45] and Ogaji et al. [30] in their studies.

About seventy percent of the respondents indicated that they did not perceive themselves to be at risk of HIV infection because they do not engage in unprotected sex. Among African-American, Lin et al. [44] found that most students did not consider themselves as a high-risk group for HIV infection. Notably, individuals who did not consider themselves to be at risk of acquiring HIV, showed relatively low 
interest in the uptake of HTS. Louis [46] states that HIV testing behavior was linked to an individual's perceived vulnerability and severity of the threat. If the risk of infection was perceived low, an individual was less likely to utilize HTS.

The present study's respondents regarded the attitude of healthcare service providers as good, and felt that they would utilize HIV testing services if the attitude of healthcare service providers was generally good. The participants who considered the attitude of healthcare providers as bad indicated that they would not utilize HIV testing services. Similarly, Dapaah [47] reported that the attitude and behavior of healthcare providers, in terms of how they relate and communicate with individuals, can influence one's willingness to utilize HTS. Individuals need to feel a sense of trust towards their healthcare providers, especially about HIV and AIDS. A warm and friendly attitude of a healthcare provider goes a long way in creating trust and the feeling of being cared for. Uwakwe et al. [48], indicated that many people would be influenced to utilize HTS if they trusted that healthcare provider would keep their results confidential.

In South Africa, Jali et al. [15] revealed that most respondents did not go for HTS due to negative attitude of healthcare providers. Some respondents did not trust that they would maintain confidentiality of their HIV results. Therefore, the relationship of trust is essential in uptake of HTS by students.

The study findings showed that most of the respondents were satisfied with the location of HTS mobile centers at university campus. However, a small percentage of the students complained that HTS was not well located, as they felt that everyone could see that they were going for HIV testing and felt that observers may assume tested positive, simply by coming out of HIV testing center with a sad look. These findings agree with those by Museve et al. [20] in Kenya, who reported that the location of HTS can influence its' uptake. In the current study, most of the respondents indicated avoiding attending stand-alone centers and preferred HTS centers in hospital premises, or those integrated with other activities, so that the students' visits to HTS centers were not too obvious.

\section{Conclusions}

The results of the present study demonstrated that most of the respondents were well-informed about HTS, and revealed that their main sources of information were clinics and HIV testing awareness campaigns. The attitude of the students towards HTS was positive, as they showed willingness to utilize it. However, several factors, including stigma associated with HIV and AIDS, fear of potential HIV-positive diagnosis, low perception of risk, and negative attitude of healthcare providers, were shown to be the main contributors to low utilization of HTS among the students.

\section{Recommendations}

Workshops and awareness campaigns should be conducted to emphasize the importance of HTS in the study setting. The use of various media, such as campus radio and newsletters to promote HTS uptake among university students should also be encouraged.

\section{Acknowledgments}

We would like to thank the University of Venda, Research and Innovation Directorate, for funding this project, the School of Health Sciences, and all the respondents who participated in this project.

\section{Conflict of interest}

The authors have no conflict of interest.

\section{References}

1. Abiodun O, Sotunsa J, Ani F, Jaiyesimi E. Knowledge of HIV/AIDS and predictors of uptake of HIV counselling and testing among undergraduate students of a privately-owned university in Nigeria. BMC Res Notes 2014; 7: 639.

2. Onyeonoro UU, Emelumadu OF, Chuku A, et al. Knowledge and utilization of HIV counselling and testing services among students of a tertiary institution in Abia State, South East Nigeria. J HIV Hum Reprod 2014; doi: 10.4103/2321-9157.135743.

3. AIDS.gov; 2017. GLOBALSTATISTICS. Available at: http://www. aids.gov/hiv-aids-basics/hiv-aids-01/global-statistics/ (Accessed: 17.04.2020).

4.WHO; 2016. HIV/AIDS. Available at: http://www.who.int/mediacentre/factsheet/fs360/en (Accessed: 22.04.2017).

5. Bock P, Phiri C, Piwowar-Manning E, et al. Understanding low sensitivity of community-based HIV rapid testing: experiences from the HPTN 071 (PopART) trial in Zambia and South Africa. J Int AIDS Soc 2017; 20 (Suppl 6): 21780.

6. Department of Health; 2015. Voluntary HIV counselling and testing. Available at: http://www.kznhealth.gov.za/testing.htm (Accessed: 25.05.2020).

7. Wilson A. "Nobody Fears Aids, Mphutsi is More Fire": Disease Rumors in the Age of Aids Treatment. In: Folklore, Gender, and Aids in Malawi. New York: Palgrave Macmillan; 2013, pp. 91-118.

8. Zwetsloot A, Bevza A, Boekema T, et al. From Moral Menace to Treatable Condition: The Political and Cinematic Representation of the AIDS Epidemic. 2020.

9. Fikadie G, Bedimo M, Alamrew Z. Prevalence of voluntary counselling and testing utilization and its associated factors among Bahirdar University students. Adv Prev Med 2014; 2014: 906107.

10. Khawcharoen T, Chunloy K, Asiparnthanarak A. Uptake of HIV testing and counselling, risk perception and linkage to HIV care among Thai university students. BMC Public Health 2016; 16: 556.

11. Djibuti M, Zurashvili T, Kasrashvili T, Berg CJ. Factors associated with HIV counselling and testing behavior among undergraduates of universities and vocational technical training schools in Tbilisi, Georgia. BMC Public Health 2015; 15: 427.

12. Njau B, Covin C, Lisasi E, et al. A systematic review of qualitative evidence on factors enabling and deterring uptake of HIV self-testing in Africa. BMC Public Health 2019; 19: 1289.

13. HEAIDS (Program). HIV Prevalence and Related Factors: Higher Education Sector Study: South Africa, 2008-2009. Higher Education HIV/AIDS Programme; 2010.

14. Venugopala R. Perceptions of undergraduate students of University of KwaZulu-Natal regarding HIV counselling and testing in the year 2012. Doctoral dissertation. University of KwaZulu-Natal, Durban, South Africa; 2013. 
15. Jali NM, Tladi FM, Malema RN, Thopola MK. Attitudes and practices of students towards HIV/AIDS voluntary counselling and testing at the University of Limpopo, South Africa; 2014.

16. Sanga Z, Kapanda G, Msuya S, Mwangi R. Factors influencing the uptake of Voluntary HIV Counselling and Testing among secondary school students in Arusha City, Tanzania: a cross sectional study. BMC Public Health 2015; 15: 1-9.

17. Bekele YA, Fekadu GA. Factors associated with HIV testing among young females; further analysis of the 2016 Ethiopian demographic and health survey data. PLoS One 2020; 15: e0228783.

18. Mulu W, Abera B, Yimer M. Knowledge, attitude and practices on HIV/AIDS among students of Bahir Dar University. Science Journal of Public Health 2014; 2: 78-86.

19. Sanga Z, Kapanda G, Msuya S, Mwangi R. Factors influencing the uptake of Voluntary HIV Counseling and Testing among secondary school students in Arusha City, Tanzania: a cross sectional study. BMC Public Health 2015; 15: 1-9.

20. Museve J, Gongera EG, Labongo CL. An analysis of uptake in HIV voluntary counselling and testing services. Case of Mount Kenya University students, Kenya; 2013.

21. Bayray A. Knowledge, Attitude, and Practice of Voluntary Counselling and Testing for HIV among University Students, Tigray, Northern Ethiopia. Momona Ethiopian Journal of Science 2010; 2(1).

22. Asante KO. HIV/AIDS knowledge and uptake of HIV counselling and testing among undergraduate private university students in Accra, Ghana. Reprod Health 2013; 10: 178.

23. Haddison EC, Nguefack-Tsagué G, Noubom M, et al. Voluntary counselling and testing for HIV among high school in the Tiko health district Cameroon. Pan Afr Med J 2012; 13: 18.

24. Arimoto $\mathrm{Y}$, Ito $\mathrm{S}$, Kono H, et al. Social relationship and HIV testing at the workplace: evidence from South Africa. Internally Valid Econometric Studies, Interim Report; 2012.

25. Gadegbeku C, Saka R, Mensah B. Attitude of the youth towards Voluntary Counseling and Testing (VCT) of HIV/AIDS in Accra, Ghana. Journal Biology, Agriculture \& Healthcare 2013; 3.

26. Nubed CK, Akoachere JF. Knowledge, attitudes and practices regarding HIV/AIDS among senior secondary school students in Fako Division, South West Region, Cameroon. BMC Public Health 2016; 16: 847.

27. Weiser SD, Heisler M, Leiter K, et al. Routine HIV testing in Botswana: a population-based study on attitudes, practices, and human rights concerns. PLoS Med 2006; 3: e261.

28. Mohlabane N, Tutshana B, Peltzer K, Mwisongo A. Barriers and facilitators associated with HIV testing uptake in South African health facilities offering HIV counselling and testing. Health SA Gesondheid 2016; 21: 86-95.

29. Nnko S, Kuringe E, Nyato D, et al. Determinants of access to HIV testing and counselling services among female sex workers in subSaharan Africa: a systematic review. BMC Public Health 2019; 19: 15.

30. Ogaji DS, Oyeyemi AS, Ibrahim I. Awareness, willingness and use of Voluntary HIV testing and counseling services by students of a university in south-south Nigeria. Journal of Community Medicine and Primary Health Care 2013; 25: 36-44.

31. Addis Z, Yalew A, Shiferaw Y, et al. Knowledge, attitude and practice towards voluntary counseling and testing among university students in North West Ethiopia: a cross sectional study. BMC Public Health 2013; 13: 714.

32. Al-Khal AL, Al-Kuwari MG, Al-Khenji AH. University students' knowledge and attitude towards HIV/AIDS in Qatar. World Family Medicine Journal 2012; 99: 1-2.

33. WHO, UNAIDS. HIV Testing Services: New opportunities and ongoing challenges. 2017. Available at: https://www.unaids.org (Accessed: 26.11 .2020 ).

34. Choudhary HA, Ali RA, Altaf S. Knowledge, behaviour and attitudes regarding HIV/AIDS among undergraduate students in an Irish university. Int J Surg Med 2015; 1: 58-66.
35. Strauss M, Rhodes B, George G. A qualitative analysis of the barriers and facilitators of HIV counselling and testing perceived by adolescents in South Africa. BMC Health Serv Res 2015; 15: 250.

36. AIDS Foundation South Africa. HIV/AIDS Facts and Myths. 2020. Available at: https://www.aids.org.za (Accessed: 05.01.2020).

37. Makhubele JC, Dhlamini SA, Khoza TI. Perception and willingness of students towards HIV counselling and testing at a higher learning institution in South Africa. Journal of Human Ecology 2015; 52: $75-82$.

38. Meda L. Assessing factors influencing university students to uptake voluntary counselling and testing (VCT) of human immune deficiency virus/acquired immune deficiency syndrome (HIV/AIDS). J AIDS HIV Res 2013; 5: 173-180.

39. Woldeyohannes D, Asmamaw Y, Sisay S, Hailesselassie W, Birmeta K, Tekeste Z. Risky HIV sexual behavior and utilization of voluntary counselling and HIV testing and associated factors among undergraduate students in Addis Ababa, Ethiopia. BMC Public Health 2017; 17: 121.

40. Swann M. Economic strengthening for HIV testing and linkage to care: a review of the evidence. AIDS Care 2018; 30 (Suppl 3): 85-98.

41. Gorgens M, Longosz AF, Ketende S, et al. Evaluating the effectiveness of incentives to improve HIV prevention outcomes for young females in Eswatini: Sitakhela Likusasa impact evaluation protocol and baseline results. BMC Public Health 2020; 20: 1591.

42. Khalifa A, Eltayeb E, Alawad A. HIV-related stigma as barrier to voluntary counselling and testing among University Students in Sudan. Int J Public Health 2014; 2: 33-36.

43. Treves-Kagan S, El Ayadi AM, Pettifor A, et al. Gender, HIV testing and stigma: the association of HIV testing behaviors and community-level and individual-level stigma in rural South Africa differ for men and women. AIDS Behav 2017; 21: 2579-2588.

44. Lin CA, Roy D, Dam L, Coman EN. College students and HIV testing: Cognitive, emotional self-efficacy, motivational and communication factors. J Commun Healthc 2017; 10: 250-259.

45. Mbengo F. Factors influencing the use of voluntary counselling and testing by university students. Doctoral dissertation; 2013.

46. Louis JP. Exploring constructs of the health belief model as predictors to Haitian men's intention to screen for prostate cancer. Urol Nurs 2019; 39: 72-82.

47. Dapaah JM. Attitudes and behaviours of health workers and the use of HIV/AIDS health care services. Nurs Res Pract 2016; 2016: 5172497.

48. Uwakwe KA, Uwakwe GC, Iwu AC, et al. Knowledge, attitude and uptake of HIV voluntary counselling and testing among undergraduates in a tertiary institution in Owerri, Imo state. Eur J Pharm Med Res 2016; 3: 326-333. 